Article

\title{
Effect of the Cu Source on Optical Properties of CuZnO Films Deposited by Ultrasonic Spraying
}

\author{
Chih-Hung Hsu, Lung-Chien Chen * and Xiuyu Zhang \\ Department of Electro-Optical Engineering, National Taipei University of Technology, No.1, \\ Section 3, Chung-Hsiao E. Rd., Taipei 10608, Taiwan; E-Mails: bluerex6@ ms35.hinet.net (C.-H.H.); \\ zxy.1013@live.com (X.Z.)
}

* Author to whom correspondence should be addressed; E-Mail: ocean@ntut.edu.tw; Tel.: +886-2-2771-2171 (ext. 4634); Fax: +886-2-8773-3216.

Received: 27 December 2013; in revised form: 17 January 2014 / Accepted: 7 February 2014 / Published: 18 February 2014

\begin{abstract}
CuZnO}(\mathrm{CZO})$ films have received considerable attention, owing to their potential applications in semiconductor devices, including gas sensors or solar cells. However, exactly how these films affect the properties of CZO films by using different $\mathrm{Cu}$ sources has seldom been investigated. This study demonstrates the feasibility of preparing $\mathrm{CZO}$ films by using different $\mathrm{Cu}$ sources via a simple ultrasonic spray method, in which copper nitrate and copper acetate were used as copper sources. Optical properties of CZO films prepared by copper nitrate and copper acetate were also investigated, based on transmittance and photoluminescence measurements. Additionally, the composition and the morphology of the films were investigated using the X-ray diffraction analysis and field emission scanning electron microscopy. The results of this study demonstrate that the CZO films prepared by using copper acetate exhibit better optical properties.
\end{abstract}

Keywords: CuZnO film; copper source; optical properties

\section{Introduction}

As a wide direct bandgap (3.36 eV) II-VI compound semiconductor, zinc oxide ( $\mathrm{ZnO}$ ) has a large exciton binding energy of $60 \mathrm{mV}$ with a hexagonal wurtzite structure [1]. However, copper oxide is a semiconductor with a band gap of $1.4 \mathrm{eV}$, which absorbs strongly in a visible spectrum [2]. $\mathrm{CuZnO}$ (CZO) with different forms (e.g., thin films, nanorods and powder which is combined by $\mathrm{ZnO}$ and 
$\mathrm{CuO}$ ) has been extensively studied, owing to its potential applications in many fields, including gas sensors and solar cells [3-9]. Many studies have focused on the change of physical properties when $\mathrm{Cu}$ was induced into ZnO. Caglar et al. [10] examined the tunable optical and electrical properties of CZO films which were prepared by the sol-gel spin coating method. Shaema et al. [11] investigated the room-temperature ferromagnetic behavior of CZO nanorods. Several copper sources, including copper nitrate, copper acetate and copper chloride, have been used to prepare $\mathrm{CZO}$ films via the chemical pyrolysis method [12-14]. However, exactly how copper sources affect the physical properties of CZO films has seldom been addressed.

In this study, owing to its high growth rate, large area uniformity, and inexpensive preparation, the ultrasonic spray method is adopted to prepare CZO films by using different $\mathrm{Cu}$ sources $[14,15]$. The structures, morphologies, and properties are measured using various approaches.

\section{Results and Discussion}

\subsection{Crystalline Structure}

Figure 1 shows the XRD patterns of $\mathrm{ZnO}$ and $\mathrm{CZO}$ films deposited on glass substrates. The spectra in this study reveal broad peaks at the position of $31.86^{\circ}, 34.57^{\circ}, 36.39^{\circ}, 47.66^{\circ}$ and $56.71^{\circ}$, which correlate well with (100), (002), (101), (012), and (110) planes of the $\mathrm{ZnO}$ phase. This finding suggests that the thin film is polycrystalline and has a hexagonal wurtzite structure of $\mathrm{ZnO}$ phase. The peaks observed above closely correspond to the hexagonal wurtzite structure ZnO (JCPDF \# 75-0576). This figure also reveals that the peak intensity decreases with an increasing $\mathrm{Cu}$ concentration increased and the use of copper acetate. However, when copper nitrate is used, the intensities of (002) and (013) planes increase with an increasing $\mathrm{Cu}$ concentration. The difference in (100) and (002) planes between samples A1 and N1 implies the formation of different crystalline orientations by using different copper sources, which is also confirmed by the following SEM analysis. The strongest intensity for the samples A1 and N1 are (101) and (002) planes, respectively. In order to attain the detailed structure information, the grain size $G$ along the c-axis was calculated according to the Scherrer's equation [16]:

$$
G=\frac{0.9 \lambda}{\beta \cos \theta}
$$

where $G, \ddot{e}$, â, and è denote the grain size, the X-ray wavelength, the full width at half maximum (FWHM) in radians, and the Bragg angle of (002) or (101) peak, respectively. The grain size for the samples A1 and N1 are 44.1 and $43.9 \mathrm{~nm}$, respectively. Therefore, the crystallinity of the sample A1 using copper acetate is better slightly than that of the sample N1. In contrast to the peaks of $\mathrm{ZnO}$ film, the (002) peak of $\mathrm{CZO}$ films shifts slightly from 34.62 to $34.5^{\circ}$, indicating that the $\mathrm{Cu}$ atoms have replaced the $\mathrm{Zn}$ atoms in the films.

Figure 2 depicts the field emission scanning electronic microscopy (FESEM) images of the surface morphologies of $\mathrm{ZnO}$ and $\mathrm{CZO}$ films observed. According to this figure, the films using different copper sources significantly differ from each other in morphology. Large rods with a diameter of $2 \mu \mathrm{m}$ are observed on the surface of the $\mathrm{ZnO}$ film. According to Figure 2b,d, the diameter of small rods on the surface of CZO films prepared by using copper acetate ranges from around $0.5-1 \mu \mathrm{m}$. Additionally, the diameter and density of rods increases with an increasing $\mathrm{Cu}$ concentration. 
However, when copper nitrate is used, the morphology transforms from a sheet structure to aggregative rods. The size of sheet structures shown in Figure $2 \mathrm{f}$ is approximately $2.5 \mu \mathrm{m}$, while the diameter of a single rod shown in Figure $2 \mathrm{~g}$ is about $1.5 \mu \mathrm{m}$. The morphology structure of the films changes in a regular pattern as the copper acetate used while it changes significantly when copper nitrate is used. The different morphology structures between samples prepared by different copper sources (correlate well with the differences in their XRD patterns. The SEM images indicate that the films are both polycrystalline, which corresponds to the XRD analysis results and also implies the difficulty in controlling the morphology of the film when copper nitrate is used.

Figure 1. $\mathrm{XRD}$ patterns of $\mathrm{ZnO}$ and $\mathrm{CuZnO}(\mathrm{CZO})$ thin films using different copper sources (Reference code: JCPDF \# 75-0576 for $\mathrm{ZnO}$ ).

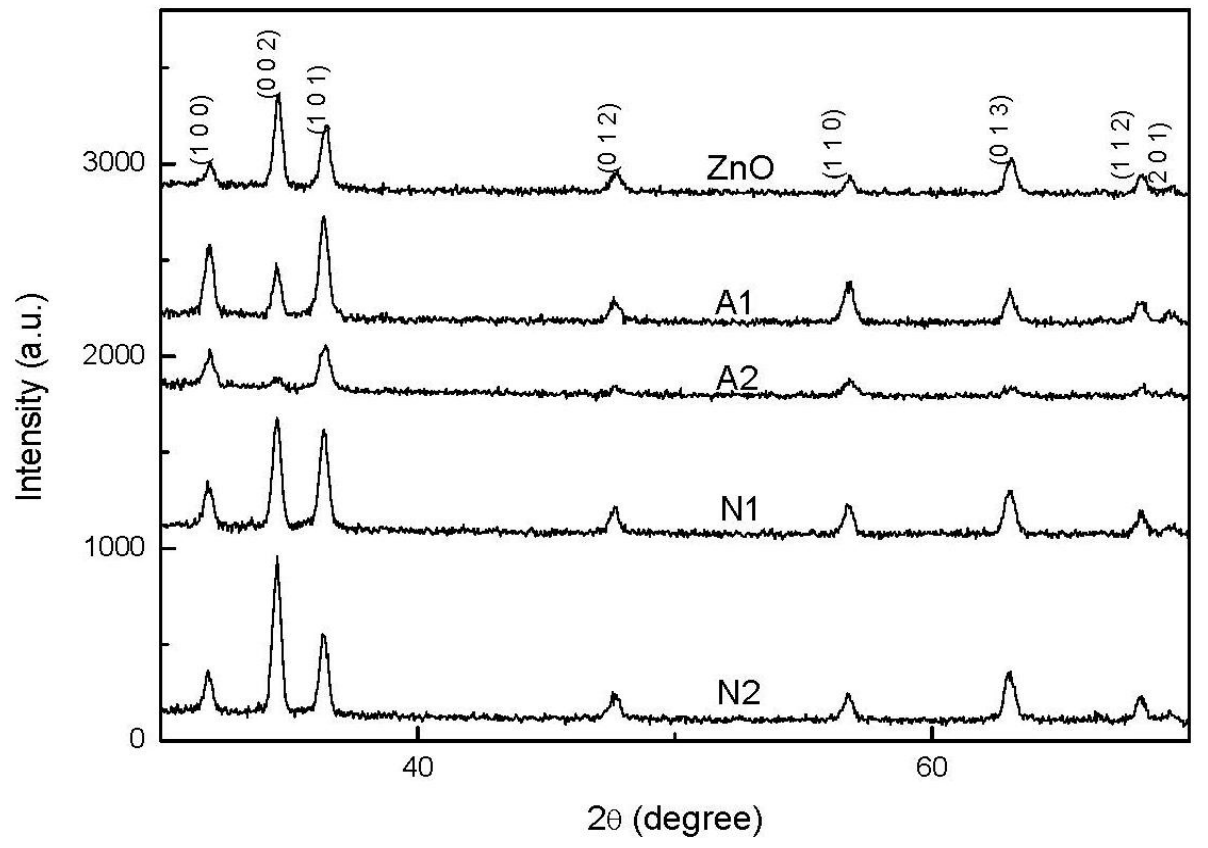

Figure 2. Field emission scanning electronic microscopy (FESEM) images of $\mathrm{ZnO}$ and CZO films with different magnification: (a) $\mathrm{ZnO}$ with $10 \mathrm{k}$ magnification, A1 with (b) $10 \mathrm{k}$ magnification and (c) $50 \mathrm{k}$ magnification, A2 with (d) $10 \mathrm{k}$ magnification and (e) $50 \mathrm{k}$ magnification, (f) N1 and (g) N2 with $10 \mathrm{k}$ magnification.

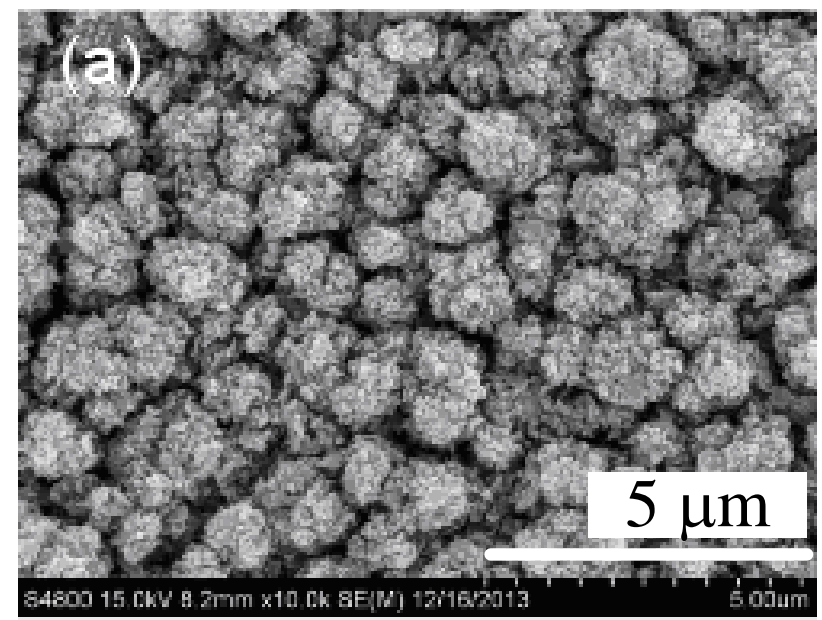


Figure 2. Cont.
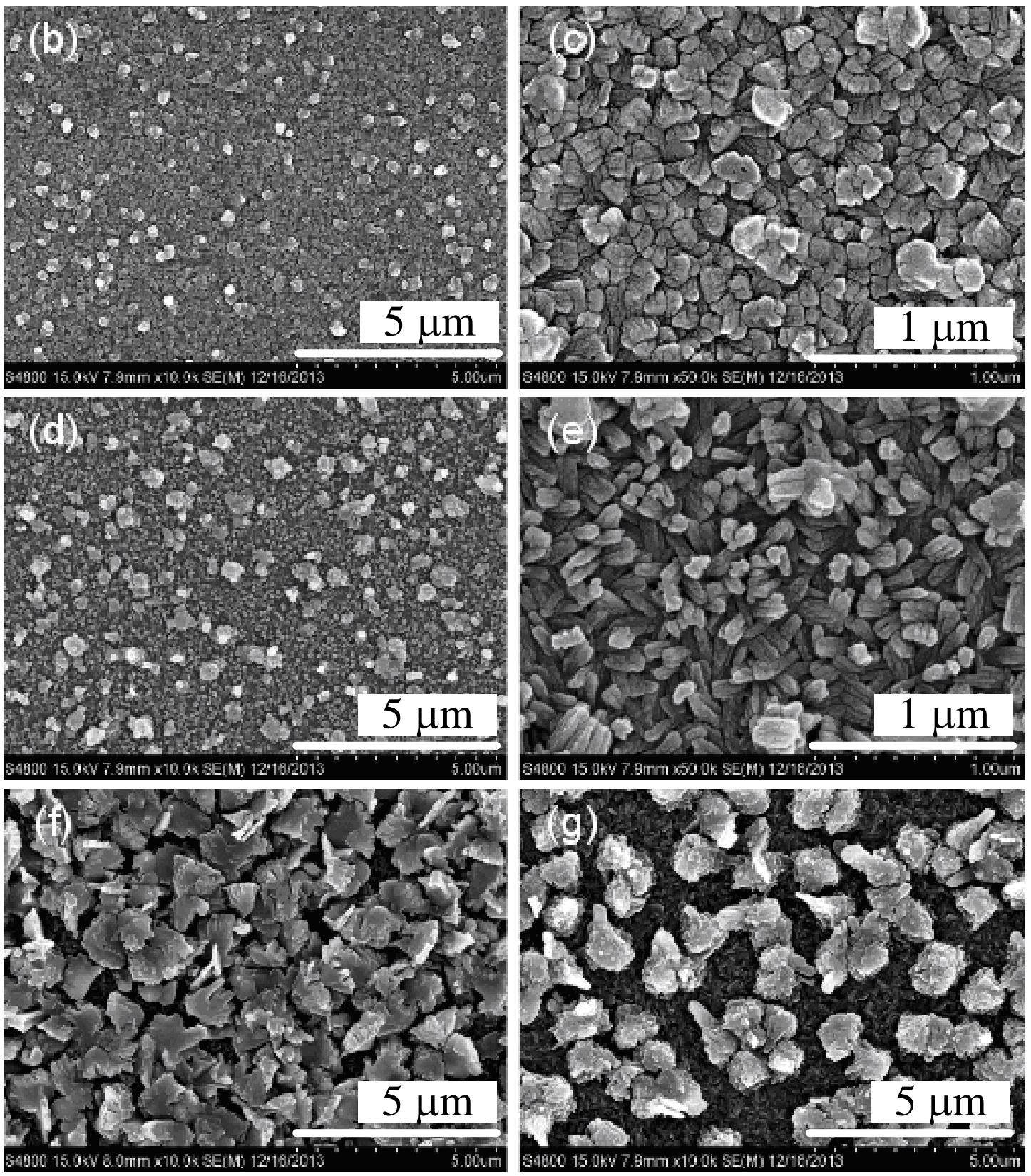

\subsection{Optical Characteristics}

Figure 3a shows the optical transmittance spectra of $\mathrm{ZnO}$ and $\mathrm{CZO}$ films ranging from $1.5 \mathrm{eV}$ $(827 \mathrm{~nm})$ to $4 \mathrm{eV}(310 \mathrm{~nm})$. The films prepared by using copper nitrate have a higher transmittance ranging from $1.5 \mathrm{eV}$ to $3.25 \mathrm{eV}$, indicating that the films have a better transparency in the visible region than the ones prepared by using copper acetate. However, when the $\mathrm{Cu}$ concentration increases and the copper source is fixed, the transmittance of the films remains nearly constant. This observation differs from that reported in [10] and may be attributed to the preparation method. Although the ratio of $\mathrm{Cu}$ to $\mathrm{Zn}$ ions in the prepared films is determined by the precursor solution, controlling the exact reacting ratio is rather difficult. When the $\mathrm{Cu}$ concentration increases in the precursor solution, the amount of $\mathrm{Cu}$ ions incorporated into the films may not increase high enough to influence the transmittance. 
The direct optical band gap $E_{\mathrm{g}}$ of the films (Figure $3 \mathrm{~b}$ ) is obtained from the transmission spectra by using the following relationships:

$$
\begin{gathered}
\alpha d=-\ln T \\
(\alpha h v)^{2}=A\left(h v-E_{g}\right)
\end{gathered}
$$

where $\alpha$ is the absorption coefficient values; $d$ is the film thickness; $T$ refers to the transmittance spectra of thin films; $A$ denotes a constant; $h v$ represents the photon energy and $E_{g}$ is the optical band gap of the semiconductor.

Figure $3 b$ shows the graph of $\alpha^{2}$ versus $h v$ plots for the film using copper acetate and copper nitrate. This figure reveals that the extrapolation of the linear portion of the graph to energy axis at $(\alpha h v)^{2}=0$ produces the $E_{\mathrm{g}}$ value. The optical band gap of the films is quite close to each other. The optical band gap of $\mathrm{A} 1$, which is prepared by using copper acetate, is $3.25 \mathrm{eV}$; meanwhile, $\mathrm{N} 1$, which is prepared by using copper nitrate, is $3.26 \mathrm{eV}$. The minute difference of optical band gap may be owing to the difference of the morphology structure [15], because $\mathrm{ZnO}$ particles with different shapes have different crystalline defect contents, subsequently impacting the $E_{g}$ values [17]. We can infer that different $\mathrm{Cu}$ sources negligibly affect the optical band gap of prepared CZO films.

Figure 3. Transmittance and optical band-gap properties of the $\mathrm{ZnO}$ and $\mathrm{CZO}$ films: (a) optical transmission spectra of the ZnO and CZO films; (b) the graph of $(\alpha h v)^{2} v s$. $h v$ plots for the CZO films prepared by using copper acetate and copper nitrate and the $\mathrm{ZnO}$ film (inset).
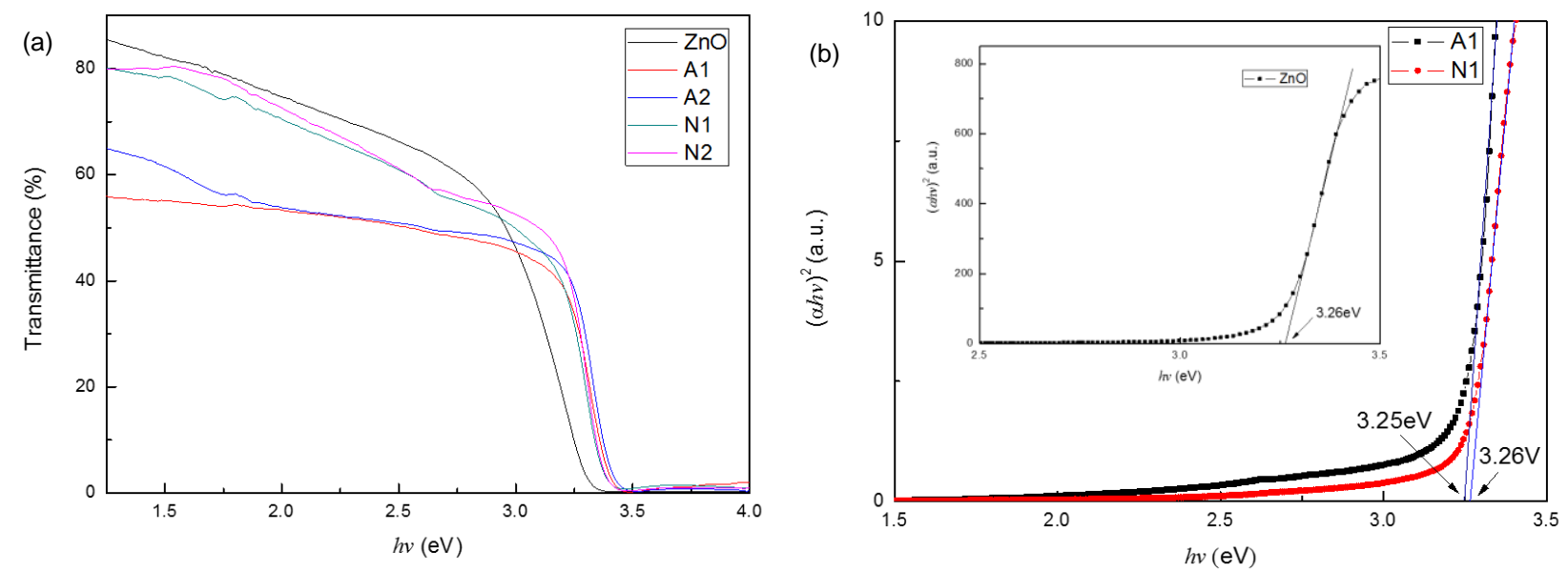

Photoluminescence (PL) measurement of the $\mathrm{ZnO}$ and $\mathrm{CZO}$ films was conducted to accumulate further information of optical properties. Figure 4 shows the PL spectra of the films. Peaks of the films are both appear at $3.26 \mathrm{eV}(380 \mathrm{~nm})$ and $1.63 \mathrm{eV}(760 \mathrm{~nm})$. The peak at $3.26 \mathrm{eV}$ corresponds to the optical band gap of the wide band gap CZO films and can be attributed to the recombination of free excitons through an exciton-exciton collision process [18,19]. Many investigations have posited that the near-IR emission at about $760 \mathrm{~nm}$ originates from defects similar to those responsible for the red emission in $\mathrm{ZnO}$, i.e., oxygen vacancy [20,21]. However, some studies have ascribed the near-IR peak to the second order diffraction of the NBE emission [22-25]. While considering the high intensity of the near-IR peak and the copper doping, we believed that the peak at $1.63 \mathrm{eV}$ is attributed to the 
oxygen vacancy. Additionally, both broad emission peaks ranging from $1.75 \mathrm{eV}$ (709 nm) to $2.25 \mathrm{eV}$ $(551 \mathrm{~nm})$ are observed, and the intensity of the film prepared by nitrate is stronger than that of the film prepared by acetate. Moreover, the broad emission is related to the deep-level emission, which is caused by the electron transformed from zinc interstitial $\left(Z n_{i}\right)$ to oxygen vacancy $\left(V_{\mathrm{o}}\right)$ defect levels [26]. Moreover, the PL spectrum of A1, which is prepared by using copper acetate, shows higher intensity of NBE emission and lower intensity of deep-level emission than those of N1, indicating that the film using copper acetate as copper source has better crystallinity.

Figure 4. Room temperature photoluminescence (PL) spectra of $\mathrm{ZnO}$ and $\mathrm{CZO}$ films. The vertical dashed lines denote the peaks position of near-band-edge (NBE) and the emission caused by oxygen vacancy.

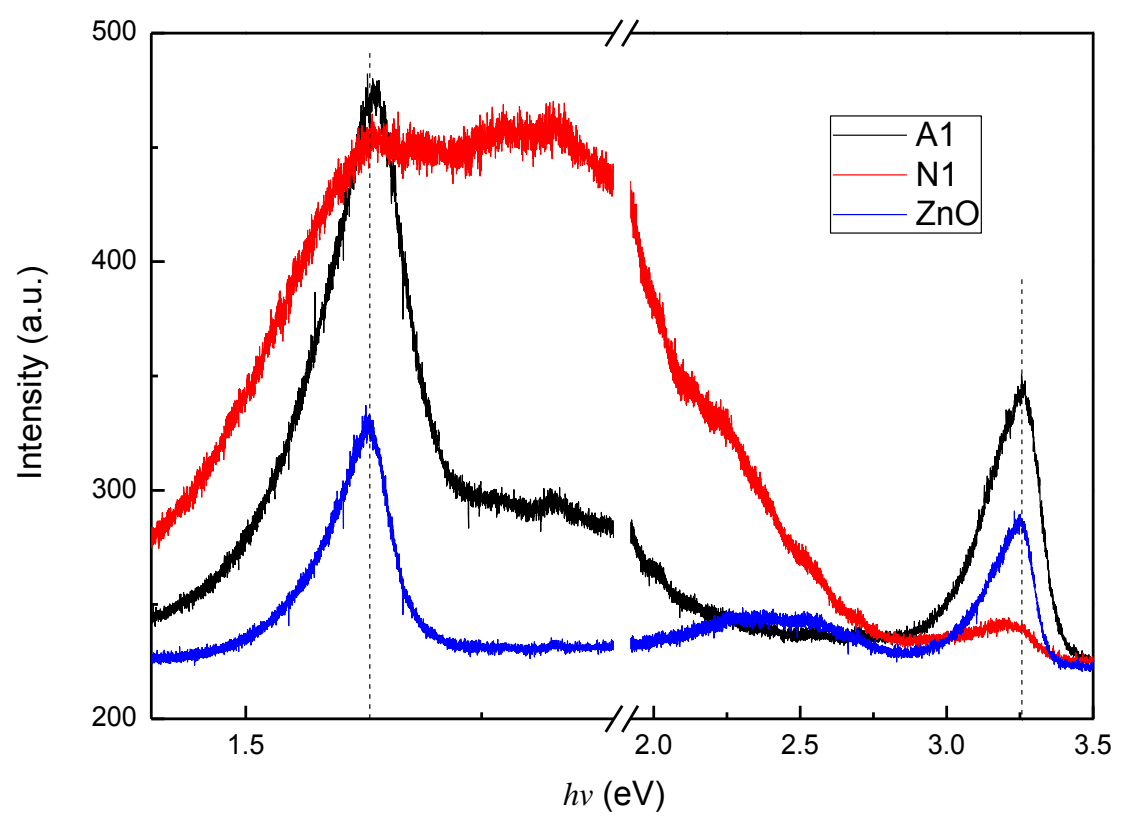

This study also investigated how copper doping affects the microscopic structure and vibration properties of prepared CZO films, based on Raman spectroscopic studies and a comparison with the $\mathrm{ZnO}$ film. Figure 5 shows the room-temperature Raman spectra of $\mathrm{ZnO}$ and $\mathrm{CZO}$ films. The Raman modes at $203 \mathrm{~cm}^{-1}, 428 \mathrm{~cm}^{-1}$ and $570 \mathrm{~cm}^{-1}$ can be attributed to the second order vibrations, $\mathrm{E}_{2}$ mode and $\mathrm{A}_{1}(\mathrm{LO})$ mode, owing to the published data for $\mathrm{c}-\mathrm{ZnO}$ respectively [27-29]. Additionally, the $\mathrm{A}_{1}(\mathrm{LO})$ mode is attributed to an electrical field induced (EFI) scattering, which also induces the inactive $\mathrm{B}_{1}$ mode at $277 \mathrm{~cm}^{-1}[30,31]$. The modes at $624 \mathrm{~cm}^{-1}$ can be ascribed to the $\mathrm{B}_{\mathrm{g}}$ mode of $\mathrm{CuO}$ phase [32,33]. The mode at $328 \mathrm{~cm}^{-1}$ should be related to the $\mathrm{E}_{2}$ (high)- $\mathrm{E}_{2}$ (low) mode of $\mathrm{ZnO}$ phase [30,34]. Comparing the spectra of $\mathrm{CZO}$ films with those of $\mathrm{ZnO}$ films reveals that the peak intensity of $\mathrm{E}_{2}$ mode decreases and the position shifts when $\mathrm{Cu}$ is incorporated into the films, and $\mathrm{B}_{1}$ and $\mathrm{B}_{\mathrm{g}}$ modes generate. The two similar spectra reveal that the microscopic structure and vibration properties of the films prepared by using different $\mathrm{Cu}$ sources resemble each other as well. 
Figure 5. Room-temperature Raman spectra of $\mathrm{ZnO}$ and $\mathrm{CZO}$ films. The spectra are vertically offset for clarity. The $\mathrm{E}_{2}$ mode shifts when $\mathrm{Cu}$ is incorporated into the films.

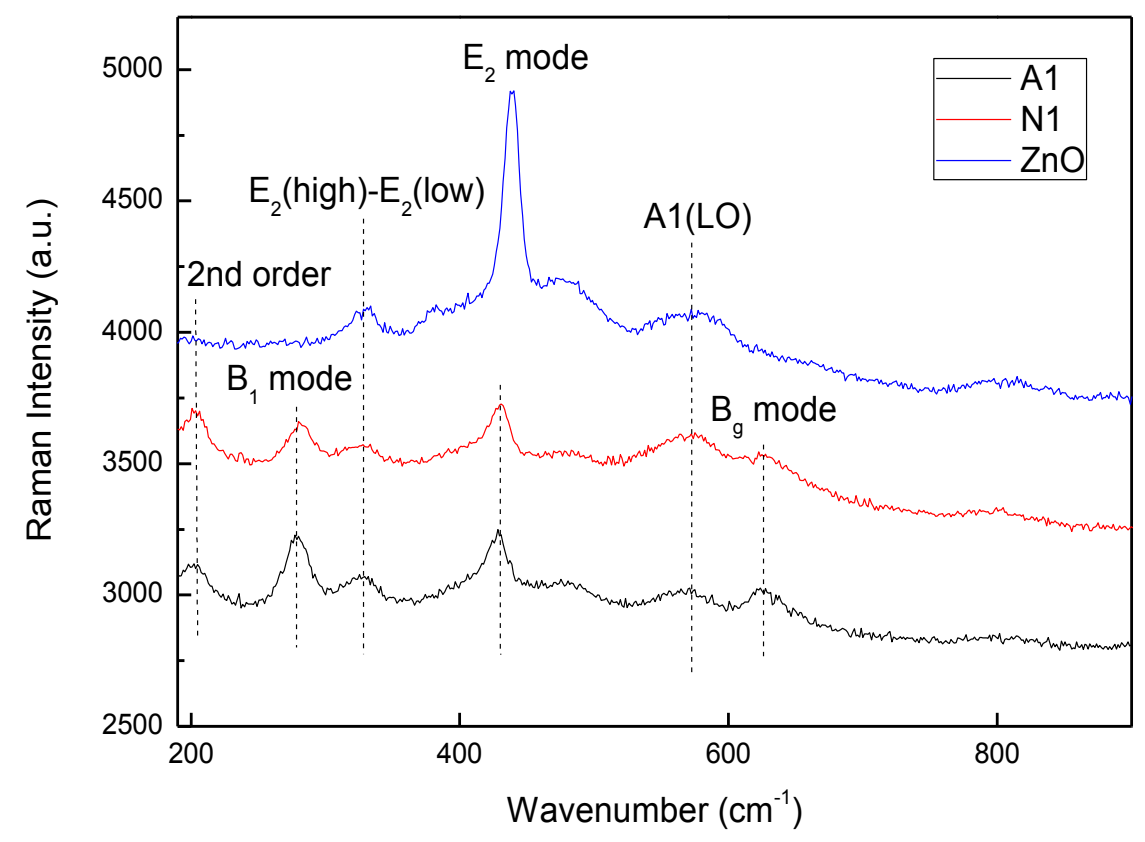

\section{Experimental Details}

CZO films were deposited by ultrasonic spraying method at atmospheric pressure on a glass substrate. Prior to deposition, the glass substrates were first cleaned in acetone and methanol. The substrates were then rinsed in de-ionized water and dried in the flowing nitrogen. Notably, the precursor solution was obtaining by selecting zinc acetate as the source of zinc, copper acetate or copper nitrate as the source of copper, respectively. Ammonium acetate was used as the $p$-type dopant nitrogen source, and the carrier concentration in the CZO films was around $(3-15) \times 10^{19} \mathrm{~cm}^{-3}$, as estimated by Hall measurements. Based on our experiences, ammonium acetate greatly facilitates the deposition of the film and improves the crystalline quality of the film. Without using ammonium acetate, depositing the film would be extremely difficult and the crystalline quality would be inferior. The molar concentration of ammonium acetate solution was $0.45 \mathrm{M}$, and the reagents of copper source (copper acetate or copper nitrate) and the zinc acetate was $0.15 \mathrm{M}$ altogether. The samples marked as A1 and A2 were prepared by using copper acetate as the copper source; the relative $\mathrm{Cu}$ and $\mathrm{Zn}$ concentrations of the precursor solutions are 1:9 and 2:8, respectively. Although the samples marked as $\mathrm{N} 1$ and $\mathrm{N} 2$ have the same relative $\mathrm{Cu}$ and $\mathrm{Zn}$ concentration as above, in this study, copper nitrate was used as the copper source. The solutions were then stirred at room temperature for $1 \mathrm{~h}$ and then moved into a commercial ultrasonic nebulizer where makes the solutions be aerosol. The aerosol was transported to the substrate by high-purity nitrogen gas, and the substrate was kept at $500{ }^{\circ} \mathrm{C}$. The deposition time lasted for $15 \mathrm{~min}$. $\mathrm{ZnO}$ film was also prepared for reference by undergoing the same process using a precursor solution without the copper source.

The crystalline microstructure of the films was determined by a PANalytical X'Pert Pro DY2840 $\mathrm{X}$-ray diffraction with $\mathrm{Cu}-\mathrm{K} \alpha$ radiation $(\lambda=0.1541 \mathrm{~nm})$ in the scanning range between $2 \theta=30^{\circ}$ and $70^{\circ}$. Surface morphology was studied by a LEO 1530 field emission scanning electron microscope 
(Zeiss, Jena, Germany). Optical transmission properties were measured in the range of 350-900 nm by using a Hitachi U-2001 Ultraviolet-Visible spectrophotometer (Hitachi, Tokyo, Japan). Photoluminescence (PL) spectra were excited by a He-Cd laser $(325 \mathrm{~nm})$, and Raman spectra were excited by a second-harmonic line of $\mathrm{Nd}^{3+}$ laser $(532 \mathrm{~nm})$, which was both collected by a Dongwoo spectrophotometer (Dongwoo, Soule, Korea) at room temperature.

\section{Conclusions}

This study elucidated the structural, morphological, and optical properties of CZO films by using different copper sources prepared via the ultrasonic spray method. The XRD patterns indicated that the films are both polycrystalline. The transmission measurement and the Raman spectra of the films revealed that the cooper sources only slightly affect the optical band gap, microscopic structure and vibration properties. The films both showed strong Near-IR emissions of photoluminescence features. Meanwhile the intensity difference of broad deep-level emission indicates that the CZO films prepared by using copper acetate have a better crystallinity than that of the film prepared by copper nitrate. Results of this study demonstrate that the prepared CZO films using copper acetate have better crystalline and optical properties than those using copper nitrate.

\section{Acknowledgments}

Financial support of this paper was provided by the National Science Council of the Republic of China under Contract No. NSC 102-2622-E-027-021-CC3.

\section{Conflicts of Interest}

The authors declare no conflict of interest.

\section{References}

1. Chen, Y.; Bagnall, D.M.; Koh, H.; Park, K.; Hiraga, K.; Zhu, Z.; Yao, T. Plasma assisted molecular beam epitaxy of $\mathrm{ZnO}$ on c-plane sapphire: Growth and characterization. J. Appl. Phys. 1998, 84, 81-98.

2. Ghijsen, J.; Tjeng, L.H.; van Elp, J.; Eskes, H.; Westerink, J.; Sawatzky, G.A. Electronic structure of $\mathrm{Cu}_{2} \mathrm{O}$ and CuO. Phys. Rev. B 1988, 38, 322-330.

3. Yoon, D.H.; Yu, J.H.; Choi, G.M. $\mathrm{CO}$ gas sensing properties of $\mathrm{ZnO}-\mathrm{CuO}$ composite. Sens. Actuators B 1998, 46, 15-23.

4. Muhamad, E.N.; Irmawati, R.; Taufiq-Yap, Y.H.; Abdullah, A.H.; Kniep, B.L.; Girgsdies, F.; Ressler, T. Comparative study of $\mathrm{Cu} / \mathrm{ZnO}$ catalysts derived from different precursors as a function of aging. Catal. Today 2008, 131, 118-124.

5. Sharma, P.K.; Dutta, R.K.; Pandey, A.C. Doping dependent room-temperature ferromagnetism and structural properties of dilute magnetic semiconductor $\mathrm{ZnO}: \mathrm{Cu}^{2+}$ nanorods. J. Magn. Magn. Mater. 2009, 321, 4001-4005.

6. Benjamin, D.Y.; Yang, P. Nanowire-based all-oxide solar cells. J. Am. Chem. Soc. 2009, 131, 3756-3761. 
7. Rahmani, M.B.; Keshmiri, S.H.; Shafiei, M.; Latham, K.; Wlodarski, W.; du Plessis, J.; Kalantar-Zadeh, K. Transition from n- to p-type of spray pyrolysis deposited $\mathrm{Cu}$ Doped $\mathrm{ZnO}$ thin films for $\mathrm{NO}_{2}$ sensing. Sens. Lett. 2009, 7, 621-628.

8. Ma, H.; Yue, L.; Yu, C.; Dong, X.; Zhang, X.; Xue, M.; Zhang, X.; Fu, Y. Synthesis, characterization and photocatalytic activity of $\mathrm{Cu}$-doped $\mathrm{Zn} / \mathrm{ZnO}$ photocatalyst with carbon modification. J. Mater. Chem. 2012, 22, 23780-23788.

9. Chowa, L.; Lupana, O.; Chaia, G.; Khallafa, H.; Onoa, L.K.; Cuenyaa, B.R.; Tiginyanu, I.M.; Ursaki, V.V.; Sontea, V.; Schulte, A. Synthesis and characterization of Cu-doped ZnO one-dimensional structures for miniaturized sensor applications with faster response. Sens. Actuators A Phys. 2013, 189, 399-408.

10. Caglar, Y.; Oral, D.D.; Caglar, M.; Ilican, S.; Thomas, M.A.; Wu, K.; Sun, Z.; Cu, J. Synthesis and characterization of $(\mathrm{CuO})_{x}(\mathrm{ZnO})_{1-x}$ composite thin films with tunable optical and electrical properties. Thin Solid Films 2012, 520, 6642-6647.

11. Mani, G.K.; Rayappan, J.B.B. Influence of copper doping on structural, optical and sensing properties of spray deposited zinc oxide thin films. J. Alloys Compd. 2014, 582, 414-419.

12. Wei, S.; Chen, Y.; Ma, Y.; Shao, Z. Fabrication of $\mathrm{CuO} / \mathrm{ZnO}$ composite ficom with cathodic co-electrodeposition and their photocatalytic performance. J. Mol. Catal. A Chem. 2010, 331, 112-116.

13. Lu, J.G.; Ye, Z.Z.; Wang, L.; Zhao, B.H.; Huang, J.Y. Preparation and properties of N-doped p-type $\mathrm{ZnO}$ films by solid source chemical vapor deposition with the $c$-axis parallel to the substrate. Chin. Phys. Lett. 2002, 19, 1494-1497.

14. Öztas, M.; Bedir, M. Thickness dependence of structural, electrical and optical properties of sprayed ZnO:Cu films. Thin Solid Films 2008, 516, 1703-1709.

15. Zamiria, R.; Lemosa, A.F.; Reblo, A.; Ahangar, H.A.; Ferreir, J.M.F. Effects of rare-earth (Er, La and $\mathrm{Yb}$ ) doping on morphology and structure properties of $\mathrm{ZnO}$ nanostructures prepared by wet chemical method. Ceram. Int. 2014, 40, 523-529.

16. Singh, F.; Kulriya, P.K.; Pivin, J.C. Origin of swift heavy ion induced stress in textured $\mathrm{ZnO}$ thin films: An in situ X-ray diffraction study. Solid State Commun. 2010, 150, 1751-1754.

17. Suwanboon, S.; Amornpitoksuk, P.; Bangrak, P.; Sukolrat, A.; Muensit, N. The dependence of optical properties on the morphology and defects of nanocrystalline $\mathrm{ZnO}$ powders and their antibacterial activity. J. Ceram. Process. Res. 2010, 11, 547-551.

18. Kong, Y.C.; Yu, D.P.; Zhang, B.; Fang, W.; Feng, S.Q. Ultraviolet-emitting ZnO nanowires synthesized by a physical vapor deposition approach. Appl. Phys. Lett. 2001, 78, 407-409.

19. Lyu, S.C.; Zhanga, Y.; Ruh, H.; Lee, H.J.; Shim, H.W.; Suh, E.K.; Lee, C.J. Low temperature growth and photoluminescence of well-aligned zinc oxide nanowires. Chem. Phys. Lett. 2002, 363, 134-138.

20. Cross, R.B.M.; de Souza, M.M.; Sankara Narayanan, E.M. A low temperature combination method for the production of $\mathrm{ZnO}$ nanowires. Nanotechnology 2005, 16, 2188-2192.

21. Lin, B.; Fu, Z.; Jia, Y. Green luminescent center in undoped zinc oxide films deposited on silicon substrates. Appl. Phys. Lett. 2001, 79, 943-945. 
22. Mahalingam, T.; Lee, K.M.; Park, K.H.; Lee, S.; Ahn, Y.; Park, J.Y.; Koh, K.H. Low temperature wet chemical synthesis of good optical quality vertically aligned crystalline $\mathrm{ZnO}$ nanorods. Nanotechnology 2007, 18, doi:10.1088/0957-4484/18/3/035606.

23. Li, W.W.; Yu, W.L.; Jiang, Y.J.; Jing, C.B.; Zhu, J.Y.; Zhu, M.; Hu, Z.G.; Tang, X.D.; Chu, J.H. Structure, optical, and room-temperature ferromagnetic properties of pure and transition-metal-(Cr, $\mathrm{Mn}$, and $\mathrm{Ni})$-doped $\mathrm{ZnO}$ nanocrystalline films grown by the sol-gel method. J. Phys. Chem. C 2010, 114, 11951-11957.

24. Lin, C.A.; Tsai, D.S.; Chen, C.Y.; He, J.H. Significant enhancement of yellow-green light emission of $\mathrm{ZnO}$ nanorod arrays using Ag island films. Nanoscale 2011, 3, 1195-1199.

25. Shinagawa, T.; Watase, S.; Izaki, M. Size-controllable growth of vertical $\mathrm{ZnO}$ nanorod arrays by a Pd-catalyzed chemical solution process. Cryst. Growth Des. 2011, 11, 5533-5539.

26. Alvi, N.H.; Ul Hasan, K.; Nur, O.; Willander, M. The origin of the red emission in $\mathrm{n}-\mathrm{ZnO}$ nanotubes/p-GaN white light emitting diodes. Nanoscale Res. Lett. 2011, 6, doi:10.1186/1556-276X-6-130.

27. Damen, T.C.; Pqrtq, S.P.S.; Tell, B. Raman effect in zinc oxide. Phys. Rev. 1996, 142, 570-574.

28. Tzolov, M.; Tzenov, U.N.; Dimova-Malinovska, D.; Kalitzova, M.; Pizzuto, C.; Vitali, G.; Zollo, G.; Ivanov, I. Vibrational properties and structure of undoped and Al-doped ZnO films deposited by RF magnetron sputtering. Thin Solid Films 2000, 379, $28-36$.

29. Nikitenko, V.A.; Plekhanov, V.G.; Mukhin, S.V.; Tkachev, M.V. Raman spectra of oxide zinc powders and single crystals. J. Appl. Spectrosc. 1996, 63, 290-292.

30. Manouni, A.E.; Manjón, F.J.; Mollar, M.; Marí, B.; Gómez, R.; López, M.C.; Ramos-Barrado, J.R. Effect of aluminium doping on zinc oxide thin films grown by spray pyrolysis. Superlattices Microstruct. 2006, 39, 185-192.

31. Manjón, F.J.; Marí, B.; Serrano, J.; Romero, A.H. Silent Raman modes in zinc oxide and related nitrides. J. Appl. Phys. 2005, 97, 053516:1-053516:4.

32. Rashad, M.; Rüsing, M.; Berth, G.; Lischka, K.; Pawlis, A. $\mathrm{CuO}$ and $\mathrm{Co}_{3} \mathrm{O}_{4}$ nanoparticles: Synthesis, characterizations, and raman spectroscopy. J. Nanomater. 2013, 714853:1-714853:6.

33. Xu, J.F.; Ji, W.; Shen, Z.X.; Li, W.S.; Tang, S.H.; Ye, X.R.; Jia, D.Z.; Xin, X.Q. Raman spectra of CuO nanocrystals. J. Raman Spectrosc. 1999, 30, 413-415.

34. Bairamov, B.H.; Heinrich, A.; Irmer, G.; Toporov, V.V.; Ziegler, E. Raman study of the phonon halfwidths and the phonon-plasmon coupling in ZnO. Phys. Status Solidi b 1983, 119, 227-234.

(C) 2014 by the authors; licensee MDPI, Basel, Switzerland. This article is an open access article distributed under the terms and conditions of the Creative Commons Attribution license (http://creativecommons.org/licenses/by/3.0/). 